\title{
Distribution of the cumulative zinc burden upon soil around galvanized pylons supporting electricity transmission lines
}

\section{Th.M. Lexmond}

Department of Soil Science and Plant Nutrition, Wageningen Agricultural University, P.O. Box 8005, NL 6700 EC Wageningen, Netherlands

Received 24 April 1987; accepted 12 May 1987

Key words: zinc, soil pollution, electricity transport, power line, pylon, dispersion by wind

\begin{abstract}
Application of galvanized steel in pylons supporting electricity transmission lines has brought about soil contamination by zinc. The distribution of the cumulative zinc burden was evaluated from the stock of zinc in the top $60 \mathrm{~cm}$ of the soil around five pylons of two different types. An adequate description of the data was obtained with a model comprising a background value of the zinc stock, a factor related to the time-integrated source strength and local variables characterizing exposure frequency and deposition rate. The exposure frequency factor was calculated as the sum of long-term directional wind frequencies over the range of azimuths over which winds move from the pylon to a given location. Deposition rate was related to distance from the pylon by an exponential decay function.
\end{abstract}

\section{Introduction}

A marked gardener's claim that the growth of green beans was inhibited in the immediate vicinity of a power pylon on sandy soil, led us to investigate the cause of this symptom. The results of soil and plant analysis indicated that it was a matter of zinc toxicity (Lexmond, unpublished).

The pylon referred to is a component of the national $380 \mathrm{kV}$ grid, a network of transmission lines linking together the main power stations in the Netherlands, with branches to Germany and Belgium. The grid is owned by the cooperating electricity production companies. Pylons supporting the transmission lines consist of a framework of galvanized steel girders built on concrete corner blocks. The owner's maintenance policy is directed towards preventing the steel from rusting. Since the protective effect of zinc coatings is only temporary under Dutch conditions, the pylons are painted. Fresh, unweathered zinc, however, is considered unsuitable as a basis for the paint. Therefore the zinc coating is allowed to weather for several years ( 5 to 
10 depending on the local corrosion rate) before the first layer of paint is put on. During these years a burden of zinc is imposed upon the soil. In the case referred to, the zinc content extractable with $0.43 \mathrm{M} \mathrm{HNO}_{3}$ (Westerhoff, 1955) in the top $20 \mathrm{~cm}$ of the soil below the pylon was $260 \mathrm{mg} \mathrm{kg}^{-1}$. At a distance of 5 to $10 \mathrm{~m}$ from the edge of the basal area it had declined to $100 \mathrm{mg} \mathrm{kg}^{-1}$ and at $50 \mathrm{~m}$ to $25 \mathrm{mg} \mathrm{kg}^{-1}$. Only the last value is within the normal range of $\mathrm{HNO}_{3}$-extractable zinc for Dutch sandy soils in agricultural use.

Jones (1983) determined the zinc content in soil near rusty pylons in Ontario, Canada, which obviously had largely lost their zinc coating. The maximum value of total zinc reported was as high as $17.4 \mathrm{~g} \mathrm{~kg}^{-1}$ in the top $5 \mathrm{~cm}$ of soil collected close to a 30 -year-old pylon. At another site a value of $8.4 \mathrm{~g} \mathrm{~kg}^{-1}$ was found in the top $5 \mathrm{~cm}$ of a bare patch of soil under the pylon. The zinc content declined rapidly with distance, soil containing $143 \mathrm{mg} \mathrm{kg}^{-1}$ in the top $10 \mathrm{~cm}$ at $10 \mathrm{~m}$ distance and $68 \mathrm{mg} \mathrm{kg}^{-1}$ (background value) at $90 \mathrm{~m}$.

In the Netherlands, electricity companies do not possess the freehold of transmission line corridors. They acquire a right of way including rights to safeguard proper functioning of the line, but they remain responsible for damage to joint users resulting from contamination. Such liability requires insight into the extent of the contamination and into its consequences. This paper reports the results of a study on the distribution of the zinc burden upon the soil, as reflected in the stock of total zinc in the top $60 \mathrm{~cm}$ around pylons in the national $380 \mathrm{kV}$ grid.

\section{Model description}

The distribution of the cumulative zinc burden is the time-integrated result of zinc transport from pylon to soil. Zinc transport is preceded by dissolution of zinc ions at the pylon surface in water supplied by rain, fog and condensation. The resulting zinc solution reaches the soil surface by flow along the pylon surface and by settling of droplets after they have become detached from the pylon surface. Droplets moving through the atmosphere are subject to the transporting action of the wind. They are carried along into a direction determined by the direction of the wind over a distance depending on wind speed and their residence time in the atmosphere. After reaching the soil surface, the zinc solution may penetrate into the soil immediately or it may run along the soil surface over some distance before penetrating. For well permeable, flat soils the significance of transport along the soil surface is considered minor and is neglected. Then, horizontal transport is entirely due to the wind.

Differences in the cumulative zinc burden between locations outside the pylon basal area can arise from differences in frequency of exposure to the zinc-containing spray and from differences in deposition rate during exposure. Exposure frequency depends on the directional wind frequency during the time when zinc-containing droplets are actually being released at the pylon surface. Since this is unknown, a long-term frequency distribution has to be used. Doing so, however, entails the implicit presupposition that both frequency distributions are congruent. Exposure frequency also depends on distance from the pylon and on pylon width, since the range of azimuths ( $\varphi$ in Fig. 1) over which winds move from the pylon to a 

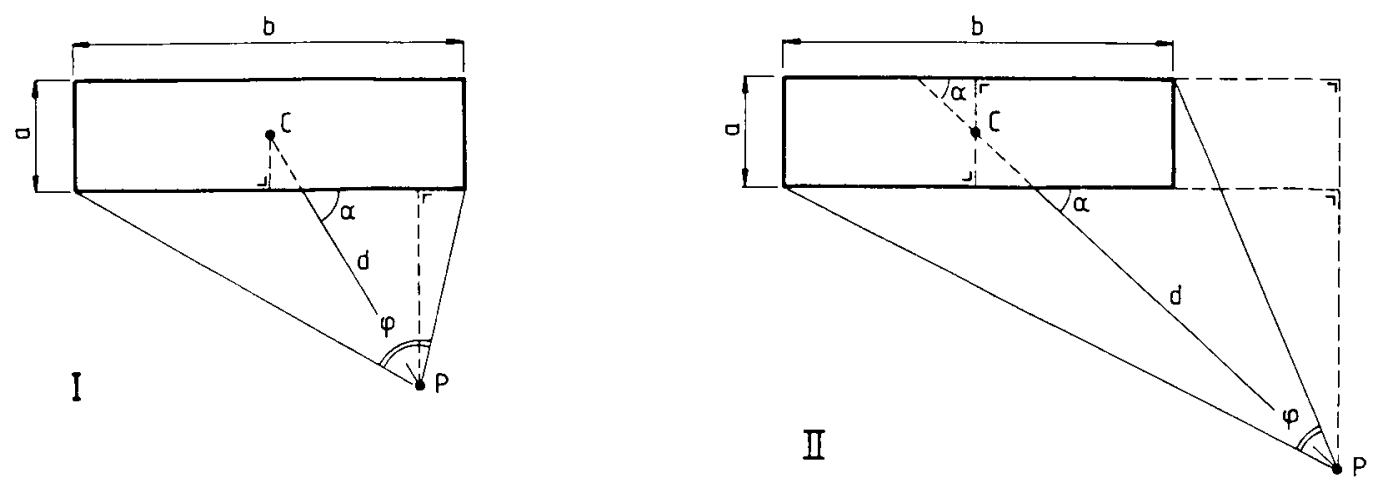

$$
\begin{aligned}
& \mathrm{I}: q=\operatorname{arctg} \frac{\frac{\mathrm{b}}{2}+\frac{\mathrm{a}}{2 \operatorname{tg} \alpha}+\mathrm{dcos} \alpha}{\mathrm{d} \sin \alpha}+\operatorname{arctg} \frac{\frac{\mathrm{b}}{2}-\frac{\mathrm{a}}{2 \operatorname{tg} \alpha}-\mathrm{dcos} \alpha}{\mathrm{dsin} \alpha} \\
& \text { II: } \varphi=\operatorname{arctg} \frac{\frac{b}{2}+\frac{a}{2 \operatorname{tg} \alpha}+d \cos \alpha}{d \sin \alpha}-\operatorname{arctg} \frac{\frac{-b}{2}+\frac{a}{2 \operatorname{tg} \alpha}+d \cos \alpha}{d \sin \alpha}
\end{aligned}
$$

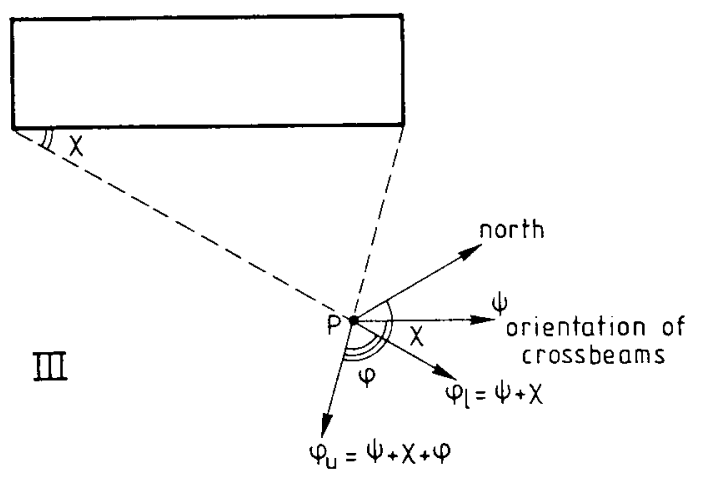

Fig. 1. Calculation of $\varphi$, the range of azimuths over which winds move from the pylon to a given point $P$, from the basal dimensions of the pylon (I, II). Lower and upper limits of $\varphi$ are indicated in III, where $\chi=$ $\operatorname{arctg}[\mathrm{d} \sin \alpha /(\mathrm{b} / 2+\mathrm{a} / 2 \operatorname{tg} \alpha+\mathrm{d} \cos \alpha)]$ (cf. I, II). The exposure frequency factor for $\mathrm{P}\left(f_{\mathrm{p}}\right)$ is defined as the sum of proportional frequencies of resultant winds blowing from the pylon over the azimuth interval $\left[\varphi_{1}, \varphi_{\mathrm{u}}\right]$.

given location is determined by these factors. Following a suggestion by McClenahen (1983), the sum of directional wind frequencies over $\varphi$ is used to estimate the exposure frequency factor $(f)$. For the sake of simplicity, $\varphi$ is calculated from the basal dimensions of the pylon, as indicated in Fig. 1.

Deposition rate at a given location is expected to decrease as distance from the pylon increases. Droplets with a relatively large diameter and, consequently, a high gravitational settling velocity and short residence time reach the soil surface within a short distance from the source. Smaller droplets may be transported over larger 
distances. Due to the selective removal of large droplets close to the source both the zinc content of the air and average gravitational settling velocity decrease as distance increases. This effect can be taken into account by introduction of an attenuation factor $a$ relating deposition rate at a given location $(j)$ to its original value close to the source $\left(j_{0}\right)$ :

$$
j=a j_{0}
$$

Since $a$ ranges between 1 at the pylon base and 0 at large distances, the relation between $a$ and distance $(d)$ might have the form of an exponential decay function:

$$
a=\exp (-k d)
$$

where the attenuation coefficient $k$ may be referred to as sedimentation coefficient. This expression has no theoretical basis, but it has been used in describing the relationship between the cumulative lead burden upon soil in the immediate vicinity of roads and distance from the road (Reiter et al., 1979). Since in that case the source is linear, exposure frequency for sites on the same side of the road is independent of distance and the relationship between cumulative lead burden and distance is entirely due to a decrease in deposition rate. Slawson \& Wigley (1976) proposed a similar 'depletion' factor in a model for cooling tower drift deposition.

The exposure frequency factor $f$ and the deposition rate attenuation factor $a$ together determine the distribution pattern of the zinc burden. They still have to be combined with the time-integrated source strength, which for a given pylon is proportional to corrosion rate and exposition time. In comparing different pylons additional factors must be taken into account, such as surface area and geometry of the pylon. The latter may affect the partitioning of zinc between the areas within and outside the pylon base. When the zinc burden is determined from changes in the stock of zinc in the soil profile, the time-integrated source strength will be characterized by a parameter of the same unit as the zinc stock, i.e. $\mathrm{g} \mathrm{m}^{-2}$. This is the ratio of the quantity of zinc distributed outside the basal area $(\mathrm{g})$ to the product of $f$ and $a$ integrated over the plane coordinates outside the basal area $\left(\mathrm{m}^{2}\right)$.

In order to complete the model a background value of the zinc stock $\left(s_{\mathrm{b}}\right)$ has to be included, representing the zinc stock excluding the contribution by the pylon.

The full model then reads as follows:

$$
s=s_{\mathrm{b}}+f \exp (-k d) S
$$

where $s$ is the zinc stock $\left(\mathrm{g} \mathrm{m}^{-2}\right)$ at a given location, $s_{\mathrm{b}}$ is its background value, $f$ is the exposure frequency factor for that location (dimensionless), $k$ is the sedimentation coefficient $\left(\mathrm{m}^{-1}\right), d$ is the distance between the location and pylon base (m) and $S$ represents the time-integrated source strength $\left(\mathrm{g} \mathrm{m}^{-2}\right)$.

The zinc stock $s$ is the measured response variable. Fixed values for the predictor variables $f$ and $d$ are assigned to each sampling location. This leaves three parameters $\left(s_{\mathrm{b}}, k\right.$ and $\left.S\right)$ whose value has to be estimated by fitting the model. 


\section{Materials and methods}

Two types of pylons have been applied in the grid, one, the most common (denoted here as type A), a single body carrying two crossbeams, the other (type B) a double body carrying three crossbeams (Fig. 2). Within each type several subtypes can be discerned. Angle pylons, applied at points where the line changes its course, are built more heavily since they have to absorb additional forces compared to support pylons. An angle and a support pylon of both types were examined. Two identical support pylons of type B were included, so as to provide an independent replication. Pylon characteristics are listed in Table 1.
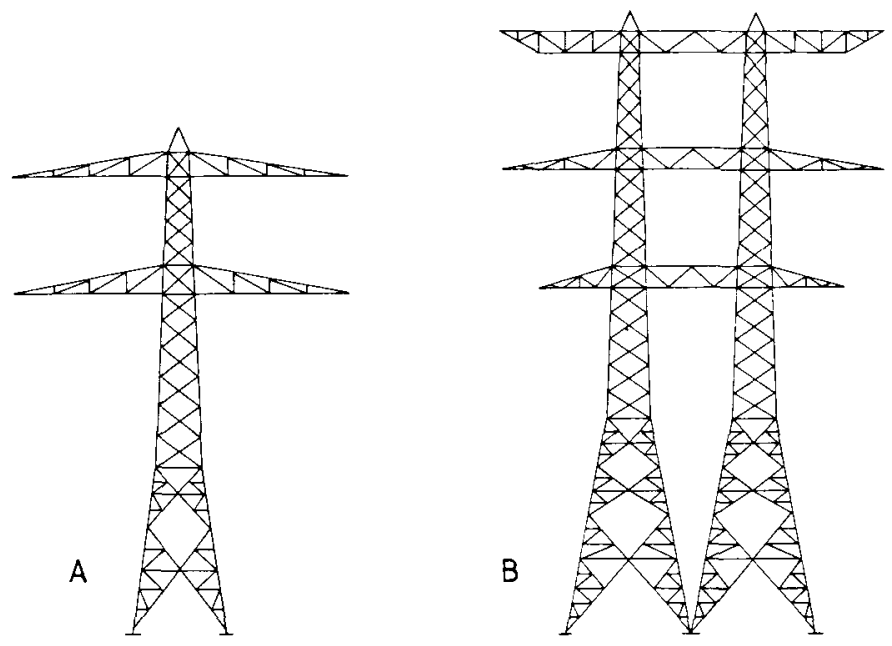

Fig. 2. Types of pylons applied in the national $380 \mathrm{kV}$ grid.

Table 1. Pylon characteristics.

\begin{tabular}{llllll}
\hline Section & \multicolumn{2}{l}{ Geertruidenberg-Eindhoven } & & Maasbracht-Dodewaard \\
\cline { 2 - 3 } \cline { 5 - 6 } Number & 49,51 & 55 & & 131 & 151 \\
Type & $\mathrm{B}$ & $\mathrm{B}$ & & $\mathrm{A}$ & $\mathrm{A}$ \\
Subtype & support & angle & & support & angle \\
Height $(\mathrm{m})$ & 60 & 57 & & 49 & 46 \\
Base $(\mathrm{m} \times \mathrm{m})$ & $7.8 \times 23.8$ & $12.5 \times 25.0$ & & $9.1 \times 9.1$ & $11.1 \times 11.1$ \\
Surface area $\left(\mathrm{m}^{2}\right)$ & 1300 & 1570 & & 630 & 970 \\
Orientation of crossbeams $\left(^{\circ}\right)$ & 21 & 26 & 95 & 68 \\
Year of construction & $1967 / 68$ & $1967 / 68$ & & $1967 / 68$ & $1967 / 68$ \\
Year of 1st painting & 1974 & 1974 & & 1978 & 1978 \\
\hline
\end{tabular}


The investigation concerning type B pylons was carried out in 1983, the information on type A pylons was collected in 1984/85.

The pylons are all situated in the province of North Brabant on sandy soils. Their relatively low zinc content compared to heavier soils warrants low background values of the zinc stock. Pylon 49 is situated on a Plaggeptic Haplaquod (de Bakker, 1979), 51, 55 and 131 on Typic Haplaquods and 151 on a Typic Humaquept, all derived from cover sand (sandy, siliceous, mesic). At the site of pylon 151 the sand is loamy, at the other sites it is not.

Around each pylon eight lines of direction separated by angles of $45^{\circ}$ were measured out from the centre of the basal area, taking the orientation of the crossbeams as base. Along each line points were marked at 2, 4, 6, 8, 10, 15, 20, 40, 60 and 100 $\mathrm{m}$ (type B) or at $3,6,12,25,50$ and $100 \mathrm{~m}$ (type A) from the edge of the basal area. Occasionally, deviations from the sampling scheme had to be accepted. Soil was sampled from the layers $0-20,20-40$ and $40-60 \mathrm{~cm}$ below surface level with a set of gauge augers for stepwise sampling. At each point three cores were collected around the marking ca. $15 \mathrm{~cm}$ apart. Cores from the same depth were combined.

Samples were air-dried, passed through a 2-mm sieve and sub-sampled by hand. Their zinc content was determined after digestion with a mixture of concentrated nitric and sulphuric acid (1:1 by volume). The digestion was finished by treatment with hydrogen peroxide and boiling with water. The zinc concentration in the digest was measured by flame atomic absorption spectrometry, using the continuous spectrum of a $\mathrm{D}_{2}$ lamp for background correction. The organic matter content (OM) was determined as loss on ignition at $850^{\circ} \mathrm{C}$. It was used to estimate dry bulk density of the soil $\left(\varrho_{\mathrm{b}}\right)$. For samples with $\mathrm{OM} \leqslant 8 \mathrm{~g} \mathrm{~kg}^{-1}, \varrho_{\mathrm{b}}$ was set at $1.65 \mathrm{Mg} \mathrm{m}^{-3}$. If 8 $<\mathrm{OM}<46, \varrho_{\mathrm{b}}$ was calculated via $\varrho_{\mathrm{b}}{ }^{-1}=0.595+3.1 \times 10^{-3} \mathrm{OM}$ and if $46 \leqslant \mathrm{OM}<$ 90 via $\varrho_{\mathrm{b}}{ }^{-1}=0.629+2.4 \times 10^{-3} \mathrm{OM}$. The zinc stock per layer $\left(\mathrm{g} \mathrm{m}^{-2}\right)$ was calculated by multiplying zinc content $\left(\mathrm{g} \mathrm{Mg}^{-1}\right)$, dry bulk density $\left(\mathrm{Mg} \mathrm{m}^{-3}\right)$, and layer thickness (m). Adding up the values for the successive layers gave the zinc stock in the top 60 $\mathrm{cm}$.

The exposure frequency factor was calculated from the directional wind frequency distribution as given for Eindhoven (1949-1970) by the Werkgroep verspreiding luchtverontreiniging (1981). The wind climate at Eindhoven is considered representative for the inland (Wieringa \& Rijkoort, 1983). The station is within $30 \mathrm{~km}$ distance from the sites of investigation.

\section{Results and discussion}

\section{Vertical distribution of the zinc content}

Table 2 summarizes results of the zinc analysis for the three successive soil layers sampled around pylons 49 and 51. A full account of analytical data is given by Lexmond (1987). It is obvious that the zinc content decreases as distance increases, thus confirming that pylons act as sources of zinc. In the top $20 \mathrm{~cm}$ the zinc content is consistently higher near pylon 51 than near pylon 49 , but the reverse applies to the $20-40 \mathrm{~cm}$ layer. These differences in vertical distribution can be attributed to soil tillage. Up to a depth of ca. $30 \mathrm{~cm}$ a partly decomposed sod was observed near pylon 
Table 2. Zinc content $\left(\mathrm{mg} \mathrm{kg}^{-1}\right)$ of the soil in three successive layers given as the arithmetic mean per distance for the pylons 49 and 51 .

\begin{tabular}{|c|c|c|c|c|c|c|c|}
\hline \multirow{2}{*}{$\begin{array}{l}\text { Distance }(\mathrm{m}) \downarrow \\
\text { Depth }(\mathrm{cm}) \text { below surface }\end{array}$} & \multirow[b]{2}{*}{$\rightarrow$} & \multicolumn{3}{|l|}{49} & \multicolumn{3}{|l|}{51} \\
\hline & & $0-20$ & $20-40$ & $40-60$ & $0-20$ & $20-40$ & $40-60$ \\
\hline 2 & & 130 & 121 & 25 & 169 & 47 & 13 \\
\hline 4 & & 115 & 76 & 21 & 134 & 46 & 12 \\
\hline 6 & & 80 & 65 & 24 & 122 & 37 & 12 \\
\hline 8 & & 64 & 56 & 13 & 107 & 31 & 13 \\
\hline 10 & & 60 & 50 & 13 & 82 & 26 & 11 \\
\hline 15 & & 42 & 38 & 11 & 64 & 20 & 9 \\
\hline 20 & & 35 & 29 & 8 & 46 & 16 & 7 \\
\hline 40 & & 21 & 20 & 8 & 38 & 13 & 6 \\
\hline$\geqslant 60$ & & 16 & 18 & 8 & 31 & 13 & 7 \\
\hline
\end{tabular}

49 , indicating that the field had been ploughed up. No traces of ploughing deeper than $20 \mathrm{~cm}$ were observed near pylon 51. The increase in zinc content of the 20-40 $\mathrm{cm}$ layer at the latter site and the slight increase in the $40-60 \mathrm{~cm}$ layer close to both pylons indicate that some leaching of zinc from the top soil has occurred. Taking the samples at distances $\geqslant 60 \mathrm{~m}$ as reference, it was calculated that the increase in the zinc stock in the $40-60 \mathrm{~cm}$ layer at distances $\leqslant 10 \mathrm{~m}$ averages $8 \%$ and $5 \%$ of the total increase in the $0-60 \mathrm{~cm}$ layer for pylons 49 and 51 respectively. The selected depth of sampling is therefore considered adequate.

\section{Horizontal distribution of the zinc stock}

Fig. 3 shows the zinc stock along lines of direction east (I) and west (II) from the pylons 49 and 51 . To the east values are consistently higher, as expected considering the prevailing southwesterly and westerly winds. The relationship between zinc stock and distance closely follows an exponential function. According to Eq. 3 an exponential relation for $s(d)$ would imply that $f(d)$ is constant or exponential. The first possibility can be rejected because of the non-point nature of the source (cf. Fig. 1). The insert in Fig. 3 shows the second to be real, even though some systematic deviations occur. In general, however, the differences in $f$ between lines of direction east and west from the pylon correspond to the differences found in the zinc stock. The zinc stock decreases more rapidly than $f$ as distance increases. According to Eq. 3 this can be explained from a decrease in deposition rate as distance increases.

Fitting Eq. 3 to the collected data (non-linear regression) by the method of least squares showed error variance to be an increasing function of the response variable. Since the coefficient of variation was constant the model was refitted by the method of weighted least squares using the previously estimated values of the response variable $(\hat{s})$ to estimate weights $(1 / \hat{s})^{2}$ inversely proportional to the variance of $s$. The results are presented in Table 3. The upper part of the table shows estimates of $k$ to be less stable than those of $s_{\mathrm{b}}$ and $S$. The lower part shows that a fixed 


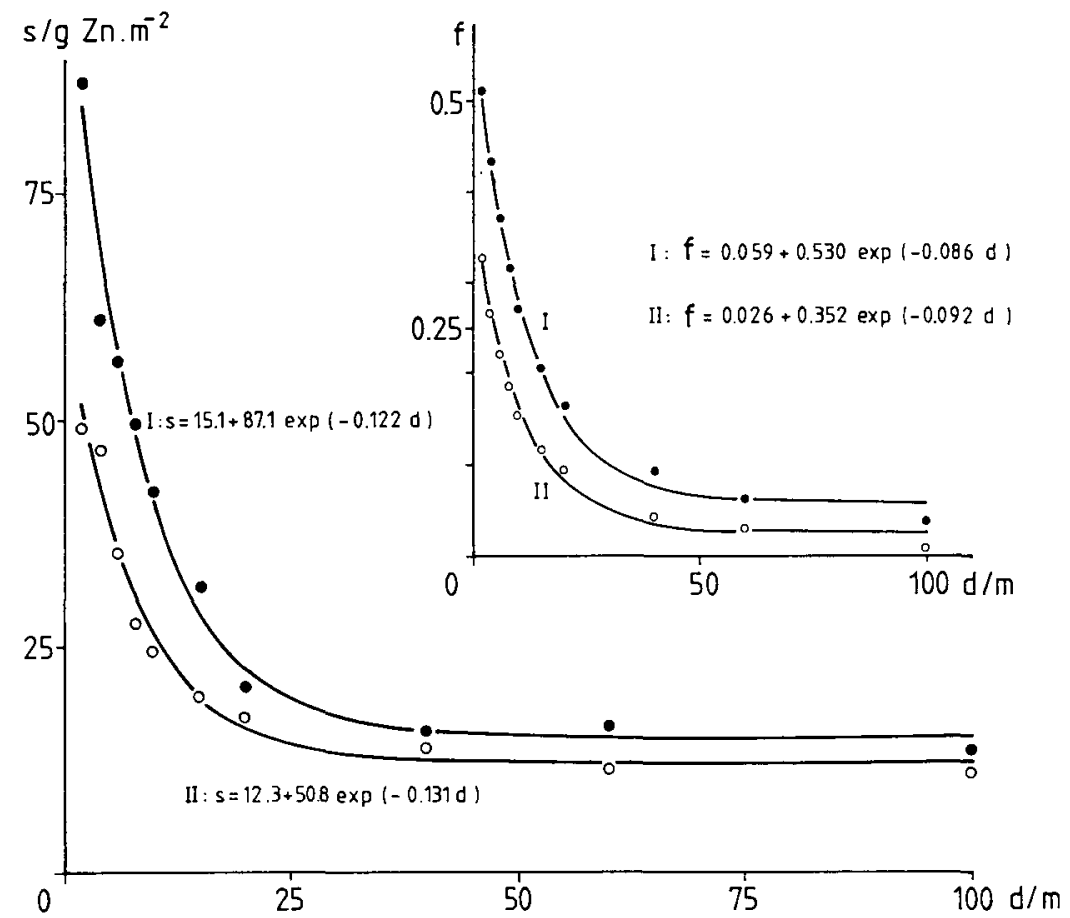

Fig. 3. Relationship between zinc stock and distance for lines of direction east (I) and west (II) from the pylons 49 and 51 . Values are the arithmetic mean over 21,66 and $111^{\circ}$ (I) and 201,246 and $291^{\circ}$ (II). The insert shows the corresponding relationships for the exposure frequency as calculated on the basis of expressions in Fig. 1 and the directional wind frequency distribution. Exponential functions fitted by ordinary least squares.

value of $k(0.03)$ can be used for all pylons without substantial effects on the coefficient of determination.

The regression is highly significant $(P<0.01)$ for each individual case. Both predictor variables contribute significantly to the regression model (partial $F$-test), the only exception being the contribution of the deposition rate attenuation factor for pylon 151 .

A test for lack of fit

A further check on model adequacy is possible because of the fact that pylons 49 and 51 are identical in every aspect. The zinc stock near these pylons has been determined at a large number (74) of corresponding locations. For each of these, two completely independent observations are available, which allow a model-independent estimate to be made of the error variance. The test procedure involves a comparison of the model-independent pure error variance and the model-dependent error variance known as lack of fit (Montgomery \& Peck, 1982). 
Table 3. Model parameters estimated by fitting Eq. 3 by the method of weighted least squares, and corresponding statistical data. A: $k$ freely adjustable. B: $k$ fixed at $0.03 \mathrm{~m}^{-1}$.

\begin{tabular}{rcccc}
\hline Pylon number & $s_{\mathrm{b}}\left(\mathrm{g} \mathrm{m}^{-2}\right)$ & $k\left(\mathrm{~m}^{-1}\right)$ & $S\left(\mathrm{~g} \mathrm{~m}^{-2}\right)$ & $R^{2 *}$ \\
$A$ & & & & \\
49 & 11.4 & 0.038 & 155 & 0.873 \\
51 & 12.1 & 0.017 & 124 & 0.812 \\
55 & 10.2 & 0.026 & 130 & 0.827 \\
131 & 14.4 & 0.048 & 153 & 0.750 \\
151 & 14.7 & 0.004 & 171 & 0.747 \\
\hline$B$ & & & & \\
49 & 11.0 & 0.03 & 148 & 0.872 \\
51 & 13.1 & 0.03 & 131 & 0.810 \\
55 & 10.5 & 0.03 & 133 & 0.826 \\
131 & 13.9 & 0.03 & 140 & 0.745 \\
151 & 17.8 & 0.03 & 184 & 0.730 \\
& & & & \\
& $n^{*}$ & $\mathrm{TSS}$ & $\mathrm{RSS}$ & $\mathrm{CV}(\%)^{*}$ \\
49 & & & & \\
51 & 76 & 22.8564 & 2.9315 & 20.0 \\
55 & 80 & 20.7342 & 3.9486 & 22.6 \\
131 & 73 & 20.4540 & 3.5533 & 22.5 \\
151 & 48 & 8.2526 & 2.1070 & 21.6 \\
\hline
\end{tabular}

* $R^{2}$ : coefficient of determination, $n$ : number of observations, TSS: total sum of squares, RSS: residual sum of squares, CV: coefficient of (residual) variation.

The weighted sum of squares (SS) due to pure error (PE) is obtained via

$$
\mathrm{SS}_{\mathrm{PE}}=\sum_{i=1}^{74} \sum_{j=1}^{2}\left(\frac{s_{i j}-\overline{s_{i}}}{\overline{s_{i}}}\right)^{2}
$$

with 74 degrees of freedom, 1 for each location. This sum of squares may be inflated if the zinc stock differs systematically between the two pylons. To check this possibility the 'block' sum of squares is calculated via

$$
\mathrm{SS}_{\mathrm{B}}=\sum_{j=1}^{2}\left(\sum_{i=1}^{74} \frac{s_{i j}-\overline{s_{i}}}{\overline{s_{i}}}\right)^{2} / 74
$$

with 1 degree of freedom.

The sum of squares for lack of fit (LOF)

$$
\mathrm{SS}_{\mathrm{LOF}}=\sum_{i=1}^{74} 2\left(\frac{\bar{s}_{i}-\hat{s}_{i}}{\hat{s}_{i}}\right)^{2}
$$

is the weighted sum of squared deviations between the mean response $\bar{s}_{i}$ at each 
location and the corresponding value $\hat{s}_{i}$ estimated by fitting the model $s=s_{\mathrm{b}}+f \exp ($ $-0.03 d) S$ by weighted least squares. The weights required for that are estimated by fitting this model by ordinary least squares. There are 71 degrees of freedom associated with $\mathrm{SS}_{\mathrm{LOF}}$, since there are 74 locations, 2 degrees of freedom are lost because 2 parameters $\left(s_{\mathrm{b}}\right.$ and $S$ ) must be estimated and 1 is considered to have been lost in the estimation of $k=0.03 \mathrm{~m}^{-1}$. The results are presented in Table 4 . The test statistic for lack of fit $\left(\mathrm{MS}_{\mathrm{LOF}} / \mathrm{MS}_{\mathrm{PE}}\right)$ is not significant $(P>0.10)$, so the model can be considered adequate. The coefficients of variation due to pure error and lack of fit amount to 20.5 and $22.8 \%$ respectively.

Table 4. Analysis of variance for the test for lack of fit.

\begin{tabular}{llcll} 
Source of variation & Sum of squares & Degrees of freedom & Mean square & $F$ \\
Lack of fit & 3.7065 & 71 & 0.0522 & 1.24 \\
Pure error & 3.1180 & 74 & 0.0421 & \\
('Block') & 0.0532 & 1 & 0.0532 & \\
(Remainder) & 3.0647 & 73 & 0.0420 & \\
\hline
\end{tabular}

Table 5. Comparison of measured and fitted values of the zinc stock (combined data pylons 49 and 51). A: direction-averaged values per distance. B: distance-averaged values per direction.

\begin{tabular}{|c|c|c|c|c|}
\hline \multirow{3}{*}{$\begin{array}{l}A \\
\text { Distance }(\mathrm{m})\end{array}$} & \multirow{3}{*}{$\begin{array}{l}\text { Number of } \\
\text { directions }\end{array}$} & \multirow{2}{*}{\multicolumn{2}{|c|}{ Zinc stock $\left(\mathrm{g} \mathrm{m}^{-2}\right)$}} & \multirow{3}{*}{$\begin{array}{l}\text { Mean relative } \\
\text { deviation }(\%)\end{array}$} \\
\hline & & & & \\
\hline & & measured & fitted & \\
\hline 2 & 8 & 69.5 & 67.7 & +1.4 \\
\hline 4 & 8 & 55.6 & 55.7 & +0.2 \\
\hline 6 & 8 & 46.8 & 45.9 & +0.1 \\
\hline 8 & 8 & 39.1 & 38.7 & -1.0 \\
\hline 10 & 8 & 33.8 & 32.9 & +2.6 \\
\hline 15 & 8 & 25.4 & 25.6 & -1.3 \\
\hline 20 & 8 & 19.5 & 21.5 & -7.8 \\
\hline 40 & 6 & 15.3 & 15.5 & +1.7 \\
\hline 60 & 6 & 14.5 & 13.5 & +7.8 \\
\hline 100 & 6 & 12.4 & 12.6 & -1.6 \\
\hline \multicolumn{5}{|l|}{$B$} \\
\hline \multirow[t]{2}{*}{ Direction $\left(^{\circ}\right)$} & \multirow{2}{*}{$\begin{array}{l}\text { Number of } \\
\text { distances }\end{array}$} & \multicolumn{2}{|c|}{ Zinc stock $\left(\mathrm{g} \mathrm{m}^{-2}\right)$} & \multirow{2}{*}{$\begin{array}{l}\text { Mean relative } \\
\text { deviation }(\%)\end{array}$} \\
\hline & & measured & fitted & \\
\hline 21 & 10 & 32.1 & 32.7 & +0.4 \\
\hline 66 & 10 & 47.9 & 43.4 & +9.9 \\
\hline 111 & 10 & 38.4 & 39.3 & -3.9 \\
\hline 156 & 10 & 32.7 & 33.4 & +0.1 \\
\hline 201 & 10 & 19.3 & 22.5 & -10.4 \\
\hline 246 & 7 & 39.9 & 38.1 & +0.7 \\
\hline 291 & 7 & 33.0 & 38.7 & -15.3 \\
\hline 336 & 10 & 35.6 & 30.0 & +14.0 \\
\hline
\end{tabular}


In Table 5 measured and fitted values of the zinc stock are compared. Directionaveraged relative deviations per distance are smaller than distance-averaged deviations per direction. None of the averaged deviations differs from its expected value (zero) at $P \leqslant 0.05$.

\section{Model parameters}

From data presented by Hemkes et al. (1980) completed with reasonable estimates of dry bulk density, Lexmond (1987) estimated a zinc stock value of $10.9 \mathrm{~g} \mathrm{~m}^{-2}$ for the top $60 \mathrm{~cm}$ of grassland on sandy soil (cover sand). The background values of the zinc stock found in this study (Table 3 ) are similar. In heavy clay soils, however, the background value may exceed this value by a factor of 10 .

No data are available which can be compared with the estimates of $k$ and $S$. The estimate of $k$ is not very accurate, since $\exp (-k d)$ and $f$ are highly correlated. For example, the correlation between $f$ and $\exp (-0.03 d)$ has a coefficient of 0.82 in the sampling scheme for pylons 49 and 51. By careful selection of lines of direction and distances some reduction is possible, but this correlation is a natural characteristic of the sampling population. The sedimentation coefficient $k$ measures the decrease in deposition rate as distance increases. It may be regarded as the fraction of the zinc flux which is withdrawn by sedimentation during transport over a certain small distance away from the source. The size of this fraction depends on the mean horizontal velocity of the zinc containing droplets (and thus on wind speed) and on their mean residence time in the atmosphere. Residence time depends on height of drop and gravitational settling velocity. An increase in wind speed and residence time causes $k$ to decrease. Therefore $k$ might be expressed as

$$
k \sim \bar{v}_{\mathrm{g}} /(\bar{u} \bar{H})
$$

where $\bar{v}_{\mathrm{g}}$ is the mean gravitational settling velocity $\left(\mathrm{m} \mathrm{s}^{-1}\right), \bar{u}$ is the average wind speed $\left(\mathrm{m} \mathrm{s}^{-1}\right)$ and $\bar{H}$ is the average height of drop $(\mathrm{m})$. Assuming that the droplet size distribution is the same for all pylons, two factors emerge which may influence $k$ : average wind speed and pylon height.

Average wind speed varies with site and with direction. For the sites involved in the investigation differences can be considered small. Frequency distributions of hourly averaged potential wind speeds are available per $30^{\circ}$ azimuth sectors (Wieringa \& Rijkoort, 1983). For the typical inland station of Eindhoven the average potential wind speed per sector is at most ca. $25 \%$ higher or lower than the average over all sectors. The relevant frequency distribution, however, is unknown since no information is available on the actual wind speed prevailing in the wake of the pylon during zinc transport. The average potential wind speed for the lines of direction east and west from pylons 49 and 51, referred to in Fig. 3, is 5.6 and $4.2 \mathrm{~m} \mathrm{~s}^{-1}$ respectively. The values of $k$ estimated by fitting Eq. 3 are 0.044 and $0.038 \mathrm{~m}^{-1}$ respectively and thus do not reflect this difference. The variation in height of the pylons studied is small. Average height amounts to $54.4 \mathrm{~m}$, the minimum value being $46 \mathrm{~m}$ $(85 \%)$, the maximum $60 \mathrm{~m}(110 \%)$. In view of the difficulty of estimating $k$ accurately, a possible effect of these small variations may have remained unnoticed. 
As sources of zinc, pylons are most easily characterized in regard to their potential size. The total volume of zinc incorporated equals the product of surface area and thickness of the zinc coating. The coating, applied by hot dipping, has an average thickness of $0.10-0.12 \mathrm{~mm}$ and surface area ranges between 0.6 and $1.0 \times 10^{3}$ $\mathrm{m}^{2}$ for type $\mathrm{A}$ and between 1.3 and $1.8 \times 10^{3} \mathrm{~m}^{2}$ for type $B$ pylons. The total volume of zinc per pylon thus ranges between 0.06 and $0.22 \mathrm{~m}^{3}$ and the total quantity between 0.43 and $1.5 \mathrm{Mg}$, assuming a density of $7.14 \mathrm{Mg} \mathrm{m}^{-3}$ for metallic zinc. Only part of the total quantity has been released to the environment. Data presented by Boers \& Tiemens (1984) indicate that approximately $10 \mu \mathrm{m}$ of zinc could have been oxidized before the coating was painted over. Since an unknown part of the corrosion products was still attached to the surface at the time of painting, the released fraction must have been less than $10 \%$. If the paint has been effective in reducing the rate of zinc loss, this figure may also serve as an estimate of the time-integrated source strength with regard to the soil both inside and outside the pylon basal area. This would then imply that without measures to mitigate zinc loss, values of $S$ can be reached eventually that exceed the estimated values (Table 3 ) by a factor of 10 or more. On soils with a high capacity to immobilize zinc, this would lead to zinc content levels close to the pylons which are comparable to those found by Jones (1983), i.e. of the order of $10 \mathrm{~g} \mathrm{~kg}^{-1}$ in the top $5 \mathrm{~cm}$.

For the time being, estimates of $S$ cannot be compared to the quantity of zinc incorporated in the pylons, since this would require (numerical) integration of the distribution function $f \exp (-k d)$ over the plane coordinates outside the basal area, a task not impossible but not executed yet. The values listed in Table 3B are remarkably similar and do not differ significantly. A combined estimate in which each separate estimate is weighted inversely as its variance, yields a value of $140 \mathrm{~g} \mathrm{~m}^{-2}$. This value may serve as a first guess of $S$ for comparable pylons in the inland, since the extent of zinc corrosion is more or less similar to all pylons at the time when the first layer of paint is put on.

\section{Conclusions}

The results of this study confirm that galvanized pylons act as sources of soil contamination by zinc. The zinc stock in the top soil declines rapidly with distance from the pylon. The influence of prevailing winds on the distribution pattern is consistent with the assumption that dispersion is effectuated by transport through air.

The distribution of the zinc stock is adequately described by a model comprising a background value of the zinc stock, a factor related to the time-integrated source strength, and local variables characterizing exposure frequency and deposition rate. The exposure frequency factor for a given location can be estimated from a long-term directional wind frequency distribution as the sum of directional wind frequencies over the range of azimuths over which winds move from the pylon to this location. Deposition rate decreases as distance to the source increases. The attenuation factor can be estimated from distance via an exponential decay function.

An evaluation of the damage to agriculture resulting from the zinc burden requires information on the relationship between the zinc content of the soil and yield 
or quality of the crops. This relationship will be affected by soil- and crop-related variables.

\section{Acknowledgements}

P. L. A. van Enckevort, M. Siegerist and J. Slange participated in this study. Mrs. A. H. de Wild-Wessels skilfully performed the major part of the analytical work and supervised the rest of it. The Cooperating Electricity Production Companies (SEP) at Arnhem gave financial support.

\section{References}

Bakker, H. de, 1979. Major soils and soil regions in the Netherlands. Junk, The Hague/Pudoc, Wageningen, $203 \mathrm{pp}$.

Boers, M. N. M. \& H. J. Tiemens, 1984. Corrosiveness of the environment. (In Dutch.) Pt/Procestechniek 39(2): 43-46.

Hemkes, O. J., A. Kemp \& L. W. van Broekhoven, 1980. Accumulation of heavy metals in soil due to annual dressings with sewage sludge. Netherlands Journal of Agricultural Science 28: 228-237.

Jones, R., 1983. Zinc and cadmium in lettuce and radish grown in soils collected near electrical transmission (hydro)towers. Water, Air and Soil Pollution 19: 389-395.

Lexmond, Th. M., 1987. Distribution of the zinc burden upon soil around galvanized power pylons. (In Dutch.) Reports and Communications 1987-1, Department of Soil Science and Plant Nutrition, Wageningen Agricultural University (available upon request).

McClenahen, J. R., 1983. The impact of an urban-industrial area on deciduous forest tree growth. Journal of Environmental Quality 12: 64-69.

Montgomery, D. C. \& E. A. Peck, 1982. Introduction to linear regression analysis. Wiley, New York, $504 \mathrm{pp}$.

Reiter, E. R., T. Henmi \& P. C. Katen, 1979. Modeling atmospheric transport. In: W. R. Boggess \& B. J. Wixson (Eds.), Lead in the environment, p. 73-92. Castle House, Austin, TX.

Slawson, P. R. \& T. M. L. Wigley, 1976. Calculation of cooling tower drift deposition. In: K. E. Noll \& W. T. Davis (Eds.), Power generation: air pollution monitoring and control, p. 83-106. Ann Arbor Science, Ann Arbor, MI, USA.

Werkgroep verspreiding luchtverontreiniging, 1981. Frequency distributions of air pollutant concentrations: a recommended calculation method. (In Dutch.) Staatsuitgeverij, 's-Gravenhage, $61 \mathrm{pp}$.

Westerhoff, H., 1955. Beiträge zur Kupferbestimmung im Boden. Landwirtschaftliche Forschung 7: 190-192.

Wieringa, J. \& P. J. Rijkoort, 1983. Wind climate of the Netherlands. (Dutch with English summary.) Staatsuitgeverij, 's-Gravenhage, $263 \mathrm{pp}$. 